\title{
Who Uses Smart City Services and What to Make of It: Toward Interdisciplinary Smart Cities Research
}

\author{
Miltiadis D. Lytras 1,2,* (i) and Anna Visvizi 1,3 (iD \\ 1 School of Business, Deree College-The American College of Greece, 153-42 Athens, Greece; \\ avisvizi@acg.edu \\ 2 Effat College of Engineering, Effat University, P.O. Box 34689, Jeddah, Saudi Arabia \\ 3 Effat College of Business, Effat University, P.O. Box 34689, Jeddah, Saudi Arabia \\ * Correspondence: mlytras@acg.edu; Tel.: +30-210-600-9800
}

Received: 11 May 2018; Accepted: 11 June 2018; Published: 13 June 2018

check for updates

\begin{abstract}
As research on smart cities garners increased attention and its status consolidates as one of the fanciest areas of research today, this paper makes a case for a cautious rethink of the very rationale and relevance of the debate. To this end, this paper looks at the smart cities debate from the perspectives of, on the one hand, citizens' awareness of applications and solutions that are considered 'smart' and, on the other hand, their ability to use these applications and solutions. Drawing from a detailed analysis of the outcomes of a pilot international study, this paper showcases that even the most educated users of smart city services, i.e., those arguably most aware of and equipped with skills to use these services effectively, express very serious concerns regarding the utility, safety, accessibility and efficiency of those services. This suggests that more pragmatism needs to be included in smart cities research if its findings are to remain useful and relevant for all stakeholders involved. The discussion in this paper contributes to the smart cities debate in three ways. First, it adds empirical support to the thesis of 'normative bias' of smart cities research. Second, it suggests ways of bypassing it, thereby opening a debate on the preconditions of sustainable interdisciplinary smart cities research. Third, it points to new avenues of research.
\end{abstract}

Keywords: smart cities; 'normative bias' of smart cities research; sustainable development; privacy; services; smart villages; innovation clusters; innovation networks; data protection; value adding services; international technology transfer

\section{Introduction}

Even though over the past few decades, smart cities research has transformed into a multidisciplinary field, housing a variety of domains and disciplines, it is still heavily based on computer science and engineering, with an explicit focus on how technological advances may be applied in urban spaces. As the body of literature on smart cities has developed, novel issues have been brought to the analysis, and new uses of technology have been proposed. Given the apparent relevance and usability of the findings produced in the field, and thus, the implicit policy-making potential that is inherent in the smart cities debate, it has been embraced by policy-makers at influential fora, such as the United Nations (UN), the European Union (EU), and the Organization for Economic Co-operation and Development (OECD). As a result, the status of smart cities research has consolidated as one of the fanciest research areas today.

Whereas, generally, increased interest in a given research problem indicates its potential to enhance our exploratory and explanatory capacities, this article makes a case for a cautious rethink of the very foundations and rationale behind smart cities research. Owing to its origins, smart cities research remains dominated by insights from broadly-conceived computer science and engineering. Clearly, however, it naturally lends itself to interdisciplinary (using insights and methods from more than one discipline) and 
multidisciplinary (using insights from different disciplines in parallel, not in conjunction) [1] approaches and strategies. Both require conceptual precision if research outcomes are to be valid and usable. Above all, attempts to explore a field as complex as that of smart cities requires questions about the ontology (what is that that exists) and epistemology (how we know about it) to be seriously considered. In contemporary smart cities research, this particular plea has very practical implications. These can be divided into two groups. On one hand, there is a considerable body of literature offering a detailed account of the uses and applications of highly sophisticated information and communication technologies (ICT) in urban contexts [2-5]. On the other hand, an equally vibrant debate has emerged around issues and topics more frequently associated with social sciences and humanities [6-8].

The challenge is that research originating in humanities and social sciences tends to reduce the centrality of ICT in smart cities research and, therefore, the depth and breadth of implications that emerge at the intersection of innate social problems and ICT in urban space remain underexplored. At the same time, the ICT-oriented literature [9-11] frequently resorts to, what has been termed elsewhere as, the 'normative bias' of smart cities research [12]. That is, owing to its disciplinary origins and, hence, respective authors' literacy in advanced sophisticated technologies, this body of research tends to focus on the promise that sophisticated technological advances hold for urban space at the expense of the basic consideration of factors that hamper and/or facilitate their implementation. Attempts at dwelling at this intersection exist [13-16]. Nevertheless, much more needs to be done to fully exploit it and hence, promote sustainable interdisciplinary smart cities research [17-21].

Against this backdrop, this paper looks at the smart cities debate from the complex perspective of, on one hand, citizens' awareness of applications and solutions considered 'smart' and on the other hand, their ability to use these applications and solutions. The discussion in this paper adds to the smart cities debate in two ways. First, it adds empirical support to the thesis of 'normative bias' of smart cities research. Second, it suggests ways of bypassing it and thereby, paves the way towards sustainable interdisciplinary smart cities research. To accomplish this, a multidimensional survey was constructed. It was preceded by a smaller international pilot study aimed at streamlining the foci of the larger survey. This article presents the outcomes of that pilot survey to make a case that the end users' awareness of and ability to use applications and solutions considered 'smart' in urban space are not to be taken for granted.

Indeed, the discussion in this paper highlights that even the most educated users of smart city services, i.e., those arguably most aware of and equipped with skills to use these services effectively, express very serious concerns regarding the utility, safety, accessibility and efficiency of those services. This, in turn, suggests that more pragmatism needs to be included in smart city research if its findings are to remain useful and relevant for all stakeholders involved. Against the backdrop of a novel typology of smart city services users, is argued that the value added from smart cities research is a function of the end users, i.e., citizens', ability to use the opportunities that advances in ICT bring. This includes a distinct set of skills and a particular mind-set, as well as, factors as trivial and basic as the existence of basic infrastructure, including, not only Wi-Fi, but also electricity, devices, etc.

The remainder of this paper is structured as follows. Section 2 outlines the research methodology pertaining to the survey and introduces the research model developed to pursue this study. Section 3 presents the outcomes of the survey. The key findings are discussed in Section 4. Conclusions and directions for future research are detailed in Section 5 .

\section{Research Methodology}

The insights, concerns and considerations inspired by the rich body of literature on smart cities that exists guided the process in which the research objectives of this study were formulated. These included the following questions:

- Is it possible to establish links between different user profiles and their abilities to use certain clusters of smart city services/applications?

- How different users of smart city services/applications perceive them and the value that they add? 
- How important for smart city efficiency are questions and concerns about security, privacy, ethics and others?

- Which are the examples of good practices of smart city services based on associated and perceived value from users?

- What are the perceptions of smart city users regarding the impacts of advanced ICT on the quality, reliability and sustainability of smart city infrastructure?

- What are the sustainability and policy-making implications for an evolutionary maturity model of smart city research?

To address these research objectives, a survey was developed (see [22]). This study discusses the sample collected in the pilot stage of this study. At that point, 102 responses from very clearly defined target focus groups of respondents inhabiting 28 countries had been collected. The focus group included highly educated respondents who were likely to have used smart city services over the past year. The hypothesis behind this definition of our target group was that presumably there is a positive direct correlation between the level of a respondent's education and his/her awareness and ability to use smart city services and applications. To develop the questionnaire, a research model (see Figure 1) was developed.

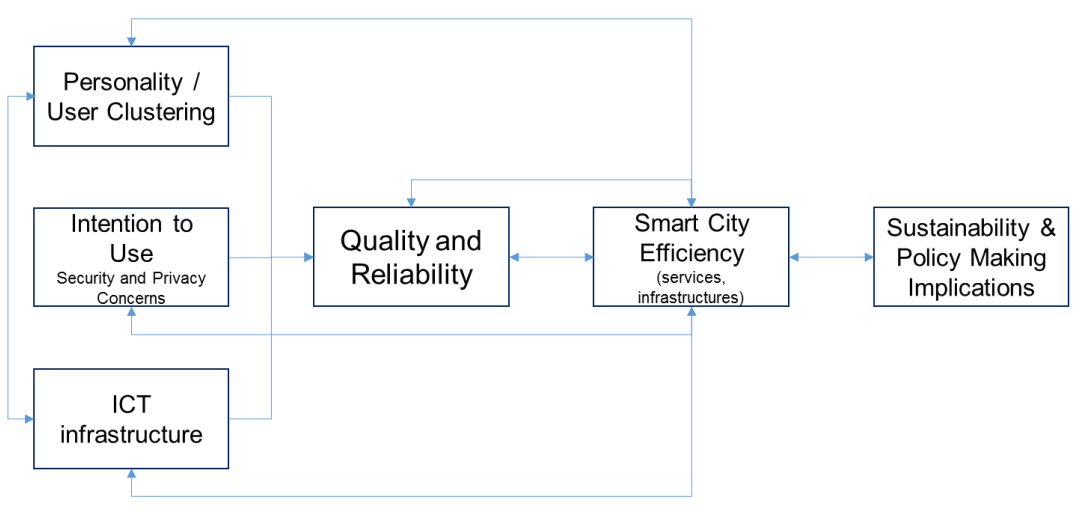

Figure 1. The research model.

As Figure 1 depicts, six research variables were identified to streamline our research. These included the following:

- The user profile, including the level of education and hence, the propensity to be aware of and use smart city services and applications and to assess their utility was used to classify users of smart city services. This pilot study targeted a focus group including highly educated respondents. In this way, this variable of research was constant in this pilot study.

- Intention to use was the second variable integrated in our research model and dealt with the aggregation of limitation factors and concerns that have impacts on the willingness of citizens to use smart city services. For the measurement of this variable, several Likert-type questions were integrated into one research tool to measure the favorable disposition of users to use smart city services.

- ICT infrastructure is related to numerous emerging and streamline technologies that serve as enablers of sophisticated smart city services. The research objective was to understand how real world smart city users value and understand this technology, and which types of technology have real impacts on value perceptions.

- The quality and reliability of smart city infrastructure is a variable that integrated the qualitative features of user interpretations for the provision and adoption of smart city services. To measure these features, several open questions and Likert-type questions were added to 
the research tool. Some of them aimed to record the best, good and worst smart city practices experienced by respondents of the survey.

- The smart city efficiency integrated several of the previous variables as prerequisites and served as a Key Performance Indicator (KPI) for the overall efficiency of the human and technological factors of smart city infrastructure. To measure this variable, we adopted a qualitative research approach by examining respondents' opinions and ideas.

- Sustainability and policy-making implications was the last research variable. The overall idea of this variable was to provide a hermeneutic analysis of the required sustainability and policy-making implications though developmental, maturity models. To measure and elaborate this research variable, we used a meta-analysis and interpretation of key findings related to the previous five variables.

These variables defined the content of the survey. Its outcomes, pertaining to the following four major issues-smart city user profiles, infrastructures and services for smart cities, policy making and participation, future smart city applications-are summarized in the following section.

\section{Analysis and Main Findings: A New Typology of the Users of Smart City Services}

\subsection{Demographics and Smart City User Profiles}

The first section of our research was dedicated to the collection of personal data and smart city user profiles. The main interest in this was related to the future analysis and comparisons between the perceptions and attitudes of users based on personality characteristics and different demographics. In our study, the focus was on users of smart city services with higher educational levels. As depicted in Table 1, almost 94\% of the respondents were PhD or Master's degree holders. The implication of this feature has a direct impact on the findings of the study. Users of smart city services with higher educational levels are more aware of technology and overall, are more prone to use smart city services and applications. Their computer literacy is higher than that of people with lower educational levels and so, their ability to use smart city services is higher.

Table 1. Educational level.

\begin{tabular}{cccc}
\hline PhD & Master's Degree & Bachelor's Degree & Undergraduate \\
\hline $66 \%$ & $28 \%$ & $4 \%$ & $2 \%$ \\
\hline
\end{tabular}

One more key characteristic of the sample included in our research related to its international coverage. Our intention was to create a sample of respondents from different countries to assess their technological maturity and the penetration of smart city services in citizens' lives and businesses. Table 2 summarizes the continents that our respondents were located in. One third of the respondents were from Asia, $44 \%$ were from Europe and almost $10 \%$ of respondents were from the Americas and the Arab Peninsula, mostly Saudi Arabia. Two percent of the respondents came from Australia. In Table 3, a detailed overview of the respondents' countries of origin is presented. Individuals from China, Spain, Greece, Taiwan, Saudi Arabia, Pakistan, Brazil and Czech Republic represented 70\% of the sample (see Table 3).

Table 2. Continent coverage.

\begin{tabular}{cc}
\hline Continent & \% in Sample \\
\hline Americas & $11 \%$ \\
Arab Peninsula & $9 \%$ \\
Asia & $34 \%$ \\
Australia & $2 \%$ \\
Europe & $44 \%$ \\
\hline
\end{tabular}


Table 3. Typology of users of smart city services.

\begin{tabular}{|c|c|c|c|}
\hline & \multicolumn{3}{|c|}{ Smart City User Clusters/Profiles } \\
\hline Feature & Apathetic User & The Concerned User & The Advocate \\
\hline Frequency of Use & Not often/seldom & Selective & $\begin{array}{c}\text { Too often and wishes to use as many } \\
\text { of these services as possible }\end{array}$ \\
\hline Typical Services & $\begin{array}{l}\text { Governmental, librarian, } \\
\text { transportation and } \\
\text { entertainment services }\end{array}$ & Variety based on preferences & Early adopter, variety of services \\
\hline Perceived Value Added & Friendliness of services & $\begin{array}{l}\text { Automation and intelligence } \\
\text { compared to traditional services }\end{array}$ & High satisfaction \\
\hline
\end{tabular}

One of the key objectives of this preliminary research study was to understand the adoption and diffusion of smart city services by the sample respondents. Given the high educational level of the sample, a key finding for further analysis was the rather high number of respondents that had not used a smart city service in the last year. In fact, $18 \%$ of the sample stated that they had not used any smart city service over the past year, while an additional $8 \%$ had used smart services to a limited extent. The confirmed users of smart city services included $74 \%$ of the sample. This is an adequate community of users of smart cities services.

Overall, users (97\%) were pleased to use smart city services; only 3\% were not. It is quite interesting from this perspective to investigate the required conditions based on users' preferences and prerequisites. Another critical objective of our analysis was the classification of smart city user profiles. In Table 4, we summarize the initial findings of the qualitative aspects of three major smart city services user profiles.

Table 4. Smart city infrastructures.

\begin{tabular}{|c|c|c|c|}
\hline Networks & Application Domains & Value-Adding Services & Policy-Making \\
\hline $\begin{array}{l}\text { Broadband cheap } \\
\text { Internet-Wi-Fi }\end{array}$ & Smart transportation services & Mobility & One-stop shop, single access points \\
\hline $\begin{array}{l}\text { Socially reliable } \\
\text { networks }\end{array}$ & Energy consumption services & Simplicity & Big Data analytics \\
\hline $\begin{array}{l}\text { Interoperable sensor } \\
\text { Nnetworks }\end{array}$ & Traffic control systems & Cloud services & Soft skills / ICT skills \\
\hline $\begin{array}{l}\text { Good electrical } \\
\text { infrustructure }\end{array}$ & Environment design & Connectivity & Information quality; ease of use \\
\hline Internet of Things & Waste collection systems & Advanced ICT & Broad access \\
\hline \multirow[t]{5}{*}{ Cutting edge ICT } & Health ICT & $\begin{array}{l}\text { Omnipresent } \\
\text { infrastructures }\end{array}$ & Large mobile penetration \\
\hline & $\begin{array}{l}\text { Automatic fraud } \\
\text { detection systems }\end{array}$ & $\begin{array}{c}\text { Real-time data } \\
\text { ecosystems }\end{array}$ & Linked interoperable services \\
\hline & $\begin{array}{c}\text { Platforms for } \\
\text { participatory decisions }\end{array}$ & Security technology & $\begin{array}{l}\text { Global access to any information } \\
\text { developed in a smart city }\end{array}$ \\
\hline & & Privacy capability & Digital literacy \\
\hline & & Local storage of Big Data & Urban planning and design \\
\hline
\end{tabular}

The main criteria used for the classification were related to the frequency of use, typical preferred services, and main concerns. Based on the findings of our survey, the following typology of users was devised: concerned users, early adopters/advocates of smart city services, and apathetic users. Table 3 offers an overview of the key features defining these three respective groups of users of smart city services. A detailed elaboration follows. 
One of the key findings was that most respondents were concerned users (Table 5). They are aware of the information technologies that support smart city services but are also very selective in their use of the services. Their main concerns are related to the data protection and security issues of smart city applications. Additionally, they feel the need to assess the effectiveness of the concept of smart cities by associating its value to relevant services. They are very much interested in the availability and sustainability of the services, while a low response rate, and misuse of collected sensitive personal information worry them the most.

Table 5. Smart city services: typology of users—-the Concerned Users.

\begin{tabular}{|c|c|}
\hline Patterns of Action & What They Say? \\
\hline $\begin{array}{l}\text { - Big Data services awareness: the main concern } \\
\text { is (personal) data protection and security. } \\
\text { There is awareness of existing technologies, but } \\
\text { there is also consensus and concerns about the } \\
\text { real effectiveness of the concept. } \\
\text { - Key perception of smart city services: smart city } \\
\text { services are services that provide automation } \\
\text { and intelligence compared to traditional services } \\
\text { - Key consideration: cost effectiveness } \\
\text { and accessibility } \\
\text { - Issues raised: human-computer interactions; } \\
\text { sustainability; the availability of these services } \\
\text { and continuity (major issue); low response time; } \\
\text { lack of access; and availability } \\
\text { Perceived problems: unauthorized access and } \\
\text { security issues. }\end{array}$ & $\begin{array}{l}\text { - "Linking the access to the mobile number definitely } \\
\text { increases the security, but it makes it very vulnerable once } \\
\text { the mobile phone device is lost or exposed and reachable } \\
\text { by a hacker. Some of the problems that occurred such as } \\
\text { access to those services were tied up with local mobile } \\
\text { phone verification which made it difficult to access at } \\
\text { sometimes especially if the user is overseas". } \\
\text { - "My main concern is technology development". } \\
\text { - "In general, I don't like that so much information is } \\
\text { collected and (could be) misused." } \\
\text { "My main concern is bugs in the app, which prevents me } \\
\text { from taking full advantage of the service and makes me } \\
\text { go to the physical facilities." } \\
\text { "Moving toward centralization for smart cities is still not } \\
\text { done fully." } \\
\text { "If the system is down, will users be able to perform their } \\
\text { tasks manually using traditional methods?" }\end{array}$ \\
\hline
\end{tabular}

Another significant profile was related the advocates of smart city services (Table 6). These individuals use smart city services extensively and promote the diffusion of advanced services for further use. The interoperability of data and systems is perceived as a value integrator towards maturity and sustainability. Last, but not least, advocates consider the quality of interfaces to be a key component for the successful adoption of smart city services. The following details the outcomes of our survey and thus, offers the full profile of the smart city services advocate.

Table 6. Smart city services: typology of users-the Advocates.

\begin{tabular}{|c|c|}
\hline Patterns of Action & What They Say? \\
\hline $\begin{array}{l}\text { - Uses smart city services regularly. } \\
\text { - } \quad \text { Hishes to use as many smart city services as possible. } \\
\text { - } \quad \text { Early adopter, enthusiast, engaged in technological } \\
\text { projects that span city smartness. } \\
\text { Typical services include governmental services and } \\
\text { services to see the events happening in the city; } \\
\text { tourism applications provided by the city; electronic } \\
\text { payments to city councils; shared bicycle and online } \\
\text { hotel reservations; administrative services (citizen } \\
\text { registration data, etc.); public service reservations; } \\
\text { traffic information; license applications; real-time bus } \\
\text { information systems and U-bike system s, etc. }\end{array}$ & $\begin{array}{l}\text { - "My main concern is about interoperability of } \\
\text { - "Opa and systems and security." } \\
\text { makes my life easier. I use online banking and } \\
\text { government services and services related to } \\
\text { entertainment." } \\
\text { "The major problems are that the websites are } \\
\text { not very friendly." } \\
\text { "I use the Taoyuan bus car, the free Wi-Fi from } \\
\text { - "Ihe government in Taiwan, etc." } \\
\text { "I have used smart city services such as } \\
\text { e-government (services) in cities in the Middle } \\
\text { East such as Dubai and Riyadh. The } \\
\text { e-government services that have been recently } \\
\text { introduced to the citizens helped to reduce the } \\
\text { pollution as well as the traffic and waste." }\end{array}$ \\
\hline
\end{tabular}


Apathetic users constituted another interesting group of respondents in our sample (Table 7). These individuals rarely use smart city services and the ones that they use, in most cases, are related to governmental and municipality processes and simple applications related to library archives and entertainment. Their main concerns are the legal terms pertaining to the use of smart city services and their limited awareness about the availability of services. Additionally, they perceive that only few of the available services are related to them. Technical problems and low-quality designs limit their willingness to use smart city services.

Table 7. Smart city services: typology of users-the Apathetic Users.

\begin{tabular}{|c|c|}
\hline Patterns of Action & What Do They Say? \\
\hline $\begin{array}{l}\text { Aware of technology options, but have limited } \\
\text { usage, for example, accessing cloud archives or } \\
\text { accessing iPhone cameras installed at home } \\
\text { while away from home only for safety purposes } \\
\text { (e.g., when they have to leave their child at } \\
\text { home with the maid). } \\
\text { Major problems encountered: services are not } \\
\text { regularly updated, nor fully exploited in terms } \\
\text { of potential. }\end{array}$ & $\begin{array}{l}\text { - "I know what a smart city service is but I } \\
\text { seldom use any of the services. I like the idea } \\
\text { but I'm worried about the privacy and being } \\
\text { manipulated too." } \\
\text { - "Occasional user; user friendliness is key." } \\
\text { - "Rather average user of smart cities services." } \\
\text { "Use a smartphone and some applications } \\
\text { - } \quad \text { related to booking on services by municipality." } \\
\text { - taxation services." } \\
\text { "I am really worried about (sharing) my data } \\
\text { over smart cities services and about my } \\
\text { privacy." } \\
\text { "I am a low intensity user. My main use is in the } \\
\text { payment of public services (electricity, water } \\
\text { supply, taxes). I also use public Wi-Fi } \\
\text { connections in the University for various tasks. } \\
\text { The main difficulty we face is the low speed and } \\
\text { availability of Internet that we have in the city." } \\
\text { "Smart city services are still at the beginning } \\
\text { (stages) (in many cases), I use some services but } \\
\text { sometimes, the (legal) rules for use are not clear; } \\
\text { the municipal authority is not ready enough for } \\
\text { such services (there are a lot of technical } \\
\text { problems, data protection is a challenge too, } \\
\text { etc.)." } \\
\text { "Hard to say, it's a new term for me." }\end{array}$ \\
\hline
\end{tabular}

\subsection{Infrastructures and Services for Smart Cities}

Another key objective of our research study was to analyze the key technologies that are perceived by respondents as the key enablers of the so-called smart city infrastructure. In Table 8, an initial analysis of findings is presented. The majority of respondents indicated that open access to the Internet and broadband is a key requirement for the realization of smart city infrastructure. Overall, networks and relevant technologies have a critical contribution to the smart city vision.

In the same basic infrastructure of networks, respondents also highlighted the importance of having reliable social networks, interoperable sensor networks, good electrical infrastructure, Internet of Things technology and cutting-edge ICT, related mostly to sensors and distributed networks. Such a finding is important and must be integrated in any maturity model for smart city evolution. At the policy-making level, this networking component must be supported by relevant policies, such as broad access programs, digital literacy, and ease of use. 
Table 8. Smart city service good practice.

\begin{tabular}{cl}
\hline Scenario & \\
\hline 1. & $\begin{array}{l}\text { "In Hong Kong, we have bus mobile apps. The major functions are (i) arrival time estimation; (ii) } \\
\text { arrival and drop off alerts; and (iii) route search." }\end{array}$ \\
\hline 2. & $\begin{array}{l}\text { "I really enjoy location aware services circulating information about nice things happening in my } \\
\text { city through my smartphone." }\end{array}$ \\
\hline "I & $\begin{array}{l}\text { "I am working in a foreign country and issued (a) visa for my family using smart services without } \\
\text { visiting an office." }\end{array}$ \\
\hline "I was pretty happy to get a car I rented using my mobile phone for (the entire)rental procedure, \\
including opening the doors of the car with no need for any other person to check the procedures."
\end{tabular}

The other critical component of smart city applications is related to a bunch of thematic applications. The provision of services for smart transportation, energy consumption, traffic control, environmental sustainability and design, waste collection systems, personalized healthcare, automatic fraud detection systems and platforms for participatory decisions has a key impact on the development and evolution of smart city infrastructure. From a policy-making perspective, the key question, given the limited resources, is determining which the required transformative and integrated plans for radical or continuous improvement initiatives within a city are. It is also important to communicate that a key requirement is the sustainability of all of these thematic and targeted services. A longitudinal strategic planning for smart cities has to provide a reliable framework for the effective management of resources, including data, services, applications and infrastructures.

One key finding of our research study was associated with the perceptions of value-adding services. The enhancement of mobility within a smart city, the advanced connectivity between citizens, applications and infrastructures as well as the interoperability of systems are promoted as key priorities for value diffusion. Ubiquitous and omnipresent infrastructures also promote the sustainability perspective of smart city infrastructure, while cloud services and local storage of Big Data increase the satisfaction of smart city infrastructure users. The simplicity of services and their user friendliness improves their adoption, while real-time data ecosystems with advanced analytics capability improve the efficiency of smart city infrastructure. Most of the respondents also stated that they require privacy capability and advanced security components.

Respondents also shared the main implications for policy-making; a one-stop shop for smart city services, single access points to network services, Big Data analytics for advanced decision-making, and required soft skills/ICT skills for the understanding and real use of services were proposed (see Table 9). 
Additionally, the smart city infrastructure vision has to be integrated into broad access plans to $\mathrm{Wi}-\mathrm{Fi}$ and free internet, large mobile penetration plans, linked interoperable services between various applications as well as the provision of global access to any information developed in a smart city. Perhaps one of the most important concerns is related to the so-called digital literacy and sophisticated urban planning and design. One of our planned publications will elaborate these initial findings further.

Long term planning for smart city services has to deal with several concerns of citizens. In our research, we tried to enlighten this aspect by asking our respondents to share their key concerns and fears. In Figure 2, a preliminary analysis is provided without further reference to user profiles and clusters. The main finding was that six factors are hermeneutic for this phenomenon, namely, security and protection $(45 \%)$, data privacy $(25 \%)$, transparency of services $(8 \%)$, ethical concerns $(6 \%)$, required soft skills $(5 \%)$, third party awareness $(5 \%)$ and the complexity of services $(4 \%)$ set some limiting factors and psychological barriers for the adoption of smart city services by users. It is a challenge for any urban design to take into consideration all of these concerns and to support an integrated strategy.

Table 9. Smart city service concerns/scenarios.

\begin{tabular}{|c|c|}
\hline Scenario & Description \\
\hline 1. & $\begin{array}{l}\text { "I dislike (it) when I register to smart city services and then other parties knock my door (to also } \\
\text { use) their services. I think there is a violation of my privacy." }\end{array}$ \\
\hline 2. & $\begin{array}{l}\text { "I have been using a third party app to get train schedules that was just an upper layer to the one } \\
\text { provided by the train company. (I) wonder what they do with the data they collect." }\end{array}$ \\
\hline 3. & "I registered my mobile phone number and I was worried about information leakage." \\
\hline 4. & $\begin{array}{l}\text { "I tried to use the online national library service and it couldn't (find) my profile. The people in the } \\
\text { library couldn't access theirs either so it seems the system was down." }\end{array}$ \\
\hline 5. & $\begin{array}{l}\text { "There is certainly room for improvement in transport ticket reservation (in) many cities (that I have } \\
\text { been to)." }\end{array}$ \\
\hline 6. & $\begin{array}{l}\text { "I used a parking app outside of my city and I paid an amount of money but I couldn't get the } \\
\text { money back (when) I didn't spend the whole amount." }\end{array}$ \\
\hline 7. & "Cameras everywhere." \\
\hline 8. & $\begin{array}{l}\text { "I installed an app that allows free internet access in a community. My main concern was } \\
\text { unauthorized access control." }\end{array}$ \\
\hline 9. & “Worried about leaving LinkedIn application data to protect my business's whereabouts." \\
\hline 10. & "The data privacy and security issues of Wechat." \\
\hline 11. & "I worry (about) the cost of Internet connection outside my country." \\
\hline 12. & "Personal data can be sold and misused by private corporations. Governments should prevent this." \\
\hline 13. & $\begin{array}{l}\text { "The address was linked with my local ID number which makes me worry about any hackers as } \\
\text { they will be able to obtain all my personal information, such as address and DOB, as well as } \\
\text { controlling some of the functionality without my approval." }\end{array}$ \\
\hline 14. & $\begin{array}{l}\text { "Once I bought a ticket to visit the Statue of Liberty in New York and the website was so confusing } \\
\text { that I paid twice and I couldn't visit it inside." }\end{array}$ \\
\hline 15. & $\begin{array}{l}\text { "I booked an online ticket from Frankfurt to Zurich from a rail service provider, The train number } \\
\text { allotted to me never goes to Zurich." }\end{array}$ \\
\hline 16. & "When using financial applications, I am always worried about security and data protection." \\
\hline 17. & $\begin{array}{l}\text { "Recently, I extended my health insurance policy. The agent on the phone asked me to provide my } \\
\text { Master Card and CSV number which I did. Clients usually provide this information through IVR } \\
\text { but not directly. I was concerned about the misuse of this information." }\end{array}$ \\
\hline 18. & $\begin{array}{l}\text { "I installed, in Taichung city, an application for a smart healthcare cloud from a third party provider } \\
\text { and felt worried about the data that this application could access/record about me." }\end{array}$ \\
\hline 19. & "All the third party applications require to (much) personal data." \\
\hline 20. & $\begin{array}{l}\text { "Many smart city apps are made for locals only and the knowledge that a foreigner or visitor has is } \\
\text { not enough to use (them)." }\end{array}$ \\
\hline 21. & $\begin{array}{l}\text { "Air BnB reservation in Brussels where I felt worried about the data privacy and reliability of } \\
\text { service as a whole." }\end{array}$ \\
\hline 22. & "I am concerned some applications are tracking my location. It doesn't feel good." \\
\hline
\end{tabular}




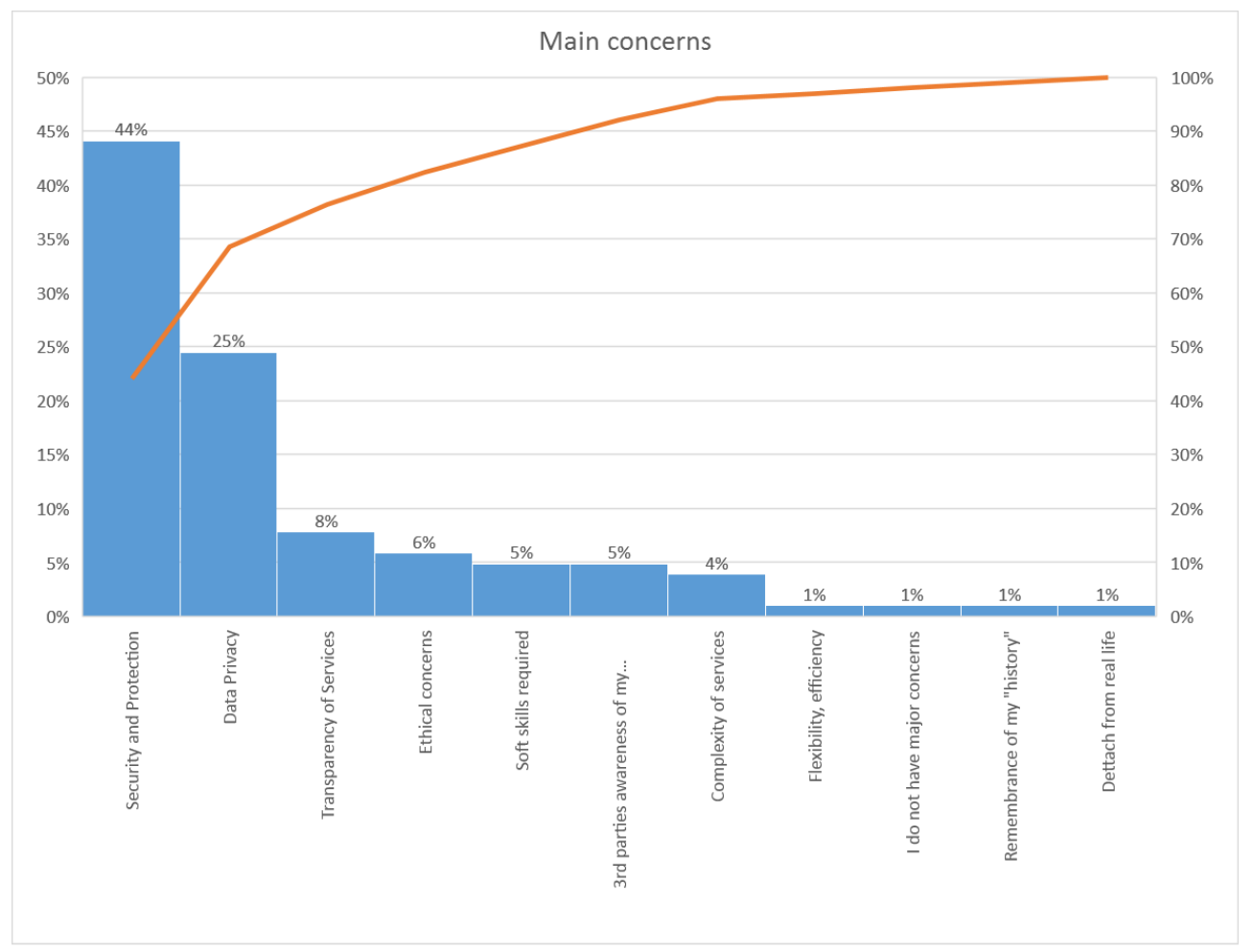

Figure 2. Main concerns of smart city users.

\subsection{Policy-Making and Participation}

The anchoring of policy-making and active participation in the smart city vision requires a deep understanding of users' perceptions and beliefs about the efficiency of the services. While technocrats and experts have developed extensive strategic models for value diffusion, the end users are the ones who interpret and feel the value of these services in their lives. In our study, we tried to interpret some best practices scenarios for the provision of smart cities to our respondents. In the next section, we provide a qualitative analysis of their responses.

To allow the classification and better discussion of these findings, we decided to integrate two value dimensions, as follows:

- Time/space dependency: The interpretive analysis of responses revealed that value perceptions of smart city services are associated with different contexts of exploitation that are highly or partly dependent on time and space.

- Data/knowledge structure: The second value dimension for the understanding of smart city services that are highly valued by the respondents of our study was related to the knowledge flow structure in terms of service provision. Our respondents implicitly and explicitly promoted the idea of knowledge flow structure as a critical differentiation factor.

With reference to these two dimensions, in Figure 3, we provide a preliminary and incomplete view of the perceptions of respondents for the clusters of value-adding services based on best practices. It is obvious from the qualitative analysis that four clusters are informing user behavior in regard to the adoption of smart city services and their user satisfaction.

1. Low time/space dependency and structured knowledge flow: In this quadrille, the smart city services are not time or space dependent and the provision of services is based on structured knowledge flows. The list of following applications was provided by our respondents as key examples of good practices; however, they do not provide an exhaustive list: the issuing of 
documents from a distance, distant activation of services, online ticketing, certificate issuing services, and open linked data applications. It is a critical challenge at the policy-making level to support and enhance these types of applications in different domains of human, social and business activities.

2. High time/space dependency and structured knowledge flow: In this quadrille, the smart city services are time or space dependent and the provision of services is based on structured knowledge flows. Typical examples include location-aware services for targeted content and service provision; real-time ticketing, smart health/traffic/finance services and electric car charging, etc. The most significant category was related to the location and context-aware services, and extensive research on this domain needs to be based on advanced profiling and advanced cognitive computing and analytic techniques and methods.

3. Low time/space dependency and unstructured knowledge flow: In this quadrille, the smart city services are not time or space dependent and the provision of services is based on unstructured knowledge flow. The notion of unstructured knowledge refers directly to microcontent contributions over social, sensor, IoT or distributed networks that require extensive data and text mining or advanced social engineering and social networks analysis methods. Our respondents emphasized two types of services directly related to this cluster: accessibility monitoring and social mining and collaboration. The continuation of our qualitative ongoing research in the near future will provide numerous more applications in this cluster.

4. High time/space dependency and unstructured knowledge flow: In this quadrille, the smart city services are time or space dependent and the provision of services is based on unstructured knowledge flow.

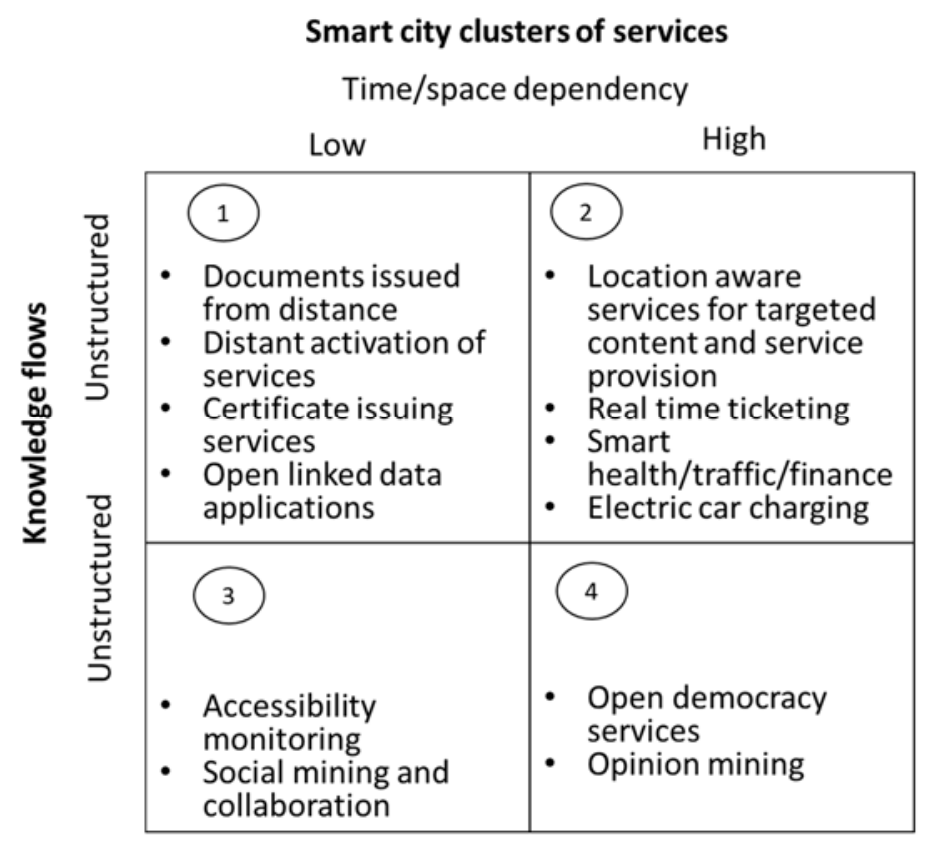

Figure 3. Smart city clusters of value-adding services based on experienced good practices.

\section{Findings of Our Research}

- $\quad$ Research objective 1: Is it possible to establish a link between different user profiles and their abilities to use certain clusters of smart city services/applications?

- $\quad$ Key finding 1: Based on the qualitative analysis and interpretation of respondents' answers, [22] we concluded that three basic user clusters exist and provide different 
contexts for the exploitation of smart city services, namely: the apathetic user, the concerned user and the advocate. For these three clusters, special features and behavior characteristics were recognized.

- $\quad$ Further research direction 1: Sophisticated matching of a variety of smart city services to these clusters to understand the preferences of users for specific services

- Policy-making and sustainability implication: The development of guidelines and strategies for the holistic support of all clusters and for the evolution of the users in the more advanced clusters.

- Research objective 2: How different users of smart city services/applications perceive them and the value that they add?

- $\quad$ Key finding 2: Most respondents were in favor of the use of smart city services. It is evident though that several barriers related to technical, behavioral, and policy-related issues limit the penetration and adoption of smart city services. There are issues related to security and privacy concerns as the poor quality of infrastructures limits the added value and perception of smart city research. It is encouraging that several smart city services are happily exploited by users, and this promotes the willingness of citizens to explore more value-adding services.

- $\quad$ Further research direction 2: Analysis of the disruptive capacity of smart city technology in citizens' lives is required, and this is an ongoing task in our research area. In our research, we found that the more the added value associated to the use of a smart city service, the greater the user satisfaction is.

- $\quad$ Policy-making and sustainability implication 2: It is evident that value perception is integrated and closely related to users' experiences and soft skills. From this perspective, a key objective of our future research is to analyze the soft skills required for the enhancement of the capacity of citizen to use smart city services. Additionally, we would like to exploit the perceptions of businesses and organizations since the use of smart city services in businesses is an emerging research domain with limited contributions.

- Research objective 3: How important for smart city efficiency are questions and concerns about security, privacy, ethics and others?

- $\quad$ Key finding 3: A bold finding of our research study is that six factors are hermeneutic for the phenomenon of smart city application adoption, namely security and protection (45\%), data privacy $(25 \%)$, transparency of services $(8 \%)$, ethical concerns $(6 \%)$, required soft skills ( $5 \%)$, third party awareness (5\%) and the complexity of services $(4 \%)$. These factors set some limitations and psychological barriers for the adoption of smart city services by users.

- $\quad$ Further research direction 3: It is necessary to further analyze these factors and to understand how all these are related to the intention to use smart city services. In regard to this purpose, we are already working on the collection of additional data to inform our research model including various aspects, such as security, ethics and quality of services.

- $\quad$ Policy-making and sustainability implication: The six factors revealed provide a context for policy consultation and design. Several policies at the macro, mezzo and micro levels are required in order to transform the concerns of users regarding opportunities for sustainable smart city services and applications.

- Research objective 4: What are the examples of good practices of smart city services based on their associated and perceived value by users?

Key finding 4: Our research study also revealed some good practices of smart city services. The following list summarizes the most significant enablers: mobility, simplicity, connectivity, 
omnipresent infrastructures, and real-time data ecosystems. The interpretation of these findings promotes the following profile of smart city services: users require the advanced mobility and availability of transparent ubiquitous services that are simple to use and allow advanced connectivity with users and other services. Additionally, the omni presence of services is highly valued.

- $\quad$ Further research direction 4: Further research on good practices in smart cities requires a case study approach that we intend to undertake for the realization of good practices in selected smart cities, including cities in Europe, Australia and the Far East.

- $\quad$ Policy-making and sustainability implication: Good practices and lessons learnt are good mechanisms to code and to disseminate methodologies, strategies and effective services in an international context. Local competencies can be benchmarked in the global context. From this point of view, one of the future research directions is to map country-specific competencies in terms of good practices for smart city research. In addition, this helps to set international benchmarks. One of the barriers in this regard is the different cultural, political, social and economic contexts of each country under investigation. Organizations like the OECD, the World Bank and the European Parliament can play key roles in this direction. A number of initiatives related to smart villages and smart city research worldwide have the potential to boost the employability, sustainability and to promote socially inclusive economic growth.

- Research objective 5: What are the perceptions of smart city users regarding the impact of advanced ICT on the quality, reliability, and sustainability of smart city infrastructure?

- $\quad$ Key finding 5: The role of ICT in the provision of smart city services is a key priority for our ongoing research. In this preliminary study, we tried to determine the key technologies that are perceived by citizens as the critical backbone and infrastructure of smart city services. The main finding was that the following technologies are recognized as the critical components of smart city infrastructure: cheap broadband Internet (Wi-Fi), socially reliable networks, interoperable sensor networks, good electrical infrastructure, Internet of Things, and cutting-edge ICT (including business intelligence, Big Data and analytics).

- $\quad$ Further research direction 5: In the era of Big Data, block chains, Internet of Things, and virtual and augmented reality, we also have to analyze the readiness of citizens and users to adopt more advanced smart city services. In addition, it is significant to understand the matching of different domains of human activity with different technologies. For this purpose, in our ongoing research, we aim to deploy an integrated qualitative and quantitative research approach to understand the impacts of emerging technologies in emerging smart city business models.

- $\quad$ Policy-making and sustainability implication: Policy-makers have to understand that technology is not the panacea, and for their effective integration into smart city and smart village research, it is necessary to model, test and implement citizen-centric policies for new emerging smart city business models. In our research agenda, the first domains to be investigated are transportation, education, and international technology transfer. We also have a special interest in the One Belt, One Road initiative of the Chinese Government and the Kingdom 2030 vision in the Kingdom of the Saudi Arabia.

- Research objective 6: What are the sustainability and policy-making implications for an evolutionary maturity model of smart city research?

- $\quad$ Key finding 6: The qualitative interpretation of responses shows that the quest of sustainability in smart cities and smart villages requires the development of an evolutionary model for sustainable growth related to different levels of smart city research maturity. 
- $\quad$ Further research direction 6: One of our key priorities in the full research study is to justify this evolutionary sustainable growth model for smart city and smart village research. Our plan is to publish the main aspects of this model in a new research paper intended to appear in late 2018 in a peer reviewed academic journal.

- $\quad$ Policy-making and sustainability implication: The integration of policy-making and sustainability in holistic smart city research and application strategies is a vital factor for social inclusive economic growth.

\section{Discussion and Conclusions}

This paper calls for a cautious rethink of the focus and rationale behind the smart cities debate from the complex perspective of the awareness and ability of citizens to use smart city services. Against the backdrop of a pilot study targeting a focus group of citizens considered to be the most ardent users of smart city services, the discussion in this paper sought to add empirical backing to the argument that smart cities research suffers from a 'normative bias', i.e., that the ICT-enhanced vision of what is technically possible does not always match the on-the-ground reality. Indeed, the outcomes of the study suggest that even among the most educated individuals, and therefore the most apt users of smart city services, several concerns clouded their willingness to use these services. A careful analysis of the respondents' profiles suggested that it is possible to divide the users of smart city services into three groups: the advocates, the concerned users and the apathetic users of smart city services. In other words, even the most educated users of smart city services, i.e., those arguably most aware of and equipped with skills to use these services effectively, express very serious concerns regarding the utility, safety, accessibility, and efficiency of those services. By querying the notion of end users' awareness of and ability to use applications and solutions considered 'smart' in the urban space, the discussion in this paper implicitly highlights that if smart cities research is to be sustainable, it also needs to be interdisciplinary. This, in turn, requires greater attention to be paid to conceptual precision, methodological meticulousness, and above all, metatheoretical awareness in smart cities research.

The research, research findings and discussion presented in this paper build on the recognition that smart cities research has great exploratory and policy-making potential and the stake, i.e., well-being of a city's inhabitants is high. Moreover, the argument in this paper builds on the assumption that a rethink of the field is necessary if dialogue between ICT- and humanities/social sciences-inclined research is to be established and consolidated in a sustainable manner. From a different angle, the argument in this paper is influenced by our conceptual work that queried the scalability of smart cities research and dwells on the added value of smart city research for the examination of the specificity of villages in view of opening the debate to smart village research [12]. What follows is that implicitly, this paper, similarly to our broader research agenda in this field, flags up the 'normative bias' inherent in smart cities research and underlines the importance of integrating smart cities and smart villages research with policy-making geared towards sustainable and inclusive growth and development. Finally, the arguments about the scalability of smart cities research and policy-making considerations places the findings of our study in the broader context of the debate on connectivity and collaboration in local, regional and global contexts. Depending on the focus of the analysis, this point of departure allows the interpretation of the findings of our research through the lens of either (i) specific policies and strategies aimed at developing infrastructure, boosting innovation and creating incentives for sophisticated entrepreneurship and entrepreneurship networks, or (ii) developments implemented around the worlds including development strategies and visions, such as the Single Market, the One Belt One Road initiative, the Saudi Arabian Kingdom 2030 Vision and many more.

The continuation of this research study is planned to appear in our edited book in Elsevier [23] and in our next special issue: Special Issue "Rethinking Security, Safety, Well-being and Happiness in Smart Cities and Smart Villages Research" http:/ / www.mdpi.com/journal/sustainability/special_ issues/smart_cities_smart_villages. 
Author Contributions: M.D.L. and A.V. contributed equally to the design, implementation, conduct of research and analysis of data and the delivery of the main findings. Both co-authors contributed equally to all phases of this research.

Acknowledgments: The authors would like to thank Effat University in Jeddah, Saudi Arabia for funding the research reported in this paper through the Research and Consultancy Institute.

Conflicts of Interest: The authors declare no conflict of interest. The funding sponsors had no role in the design of the study; in the collection, analyses, or interpretation of data; in the writing of the manuscript, and in the decision to publish the results.

\section{References}

1. Warleigh-Lack, A. Greening the European Union for legitimacy? A cautionary reading of Europe 2020. Innov. Eur. J. Soc. Sci. Res. 2011, 23, 297-311. [CrossRef]

2. Lytras, M.D.; Raghavan, V.; Damiani, E. Big data and data analytics research: From metaphors to value space for collective wisdom in human decision making and smart machines. Int. J. Semant. Web Inf. Syst. 2017, 13, 1-10. [CrossRef]

3. Lytras, M.D.; Mathkour, H.I.; Abdalla, H.; Al-Halabi, W.; Yanez-Marquez, C.; Siqueira, S.W.M. Enabling technologies and business infrastructures for next generation social media: Big data, cloud computing, internet of things and virtual reality. J. Univers. Comput. Sci. 2015, 21, 1379-1384.

4. Lytras, M.D.; Mathkour, H.I.; Abdalla, H.; Al-Halabi, W.; Yanez-Marquez, C.; Siqueira, S.W.M. An emerging-Social and emerging computing enabled philosophical paradigm for collaborative learning systems: Toward high effective next generation learning systems for the knowledge society. Comput. Hum. Behav. 2015, 5, 557-561. [CrossRef]

5. Angelidou, M.; Psaltoglou, A.; Komninos, N.; Kakderi, C.; Tsarchopoulos, P.; Panori, A. Enhancing sustainable urban development through smart city applications. J. Sci. Technol. Policy Manag. 2017. [CrossRef]

6. Lytras, M.D.; Mathkour, H.; Torres-Ruiz, M. Innovative Mobile Information Systems: Insights from Gulf Cooperation Countries and All over the World. Mob. Inf. Syst. 2016, 2016, 2439389. [CrossRef]

7. Keim, D.A. Visual exploration of large data sets. Commun. ACM 2001, 44, 38-44. [CrossRef]

8. Höjer, M.; Wangel, J. Smart sustainable cities: Definition and challenges. Adv. Intell. Syst. Comput. 2014, 310, 333-349.

9. Bi, S.; Liu, Z.; Usman, K. The influence of online information on investing decisions of reward-based crowdfunding. J. Bus. Res. 2017, 71, 10-18. [CrossRef]

10. Yin, C.; Xiong, Z.; Chen, H.; Wang, J.; Cooper, D.; David, B. A literature survey on smart cities. Sci. China Inf. Sci. 2015, 58, 1-18. [CrossRef]

11. Bibri, S.E.; Krogstie, J. On the social shaping dimensions of smart sustainable cities: A study in science, technology, and society. Sustain. Cities Soc. 2017, 29, 219-246. [CrossRef]

12. Visvizi, A.; Lytras, M.D. Rescaling and refocusing smart cities research: From mega cities to smart villages. J. Sci. Technol. Policy Mak. 2018. [CrossRef]

13. Van de Voorde, T.; Jacquet, W.; Canters, F. Mapping form and function in urban areas: An approach based on urban metrics and continuous impervious surface data. Landsc. Urban Plan. 2011, 102, 143-155. [CrossRef]

14. Lytras, M.D.; Aljohani, N.R.; Hussain, A.; Luo, J.; Zhang, X.Z. Cognitive Computing Track Chairs' Welcome \& Organization. In Proceedings of the Companion of the Web Conference, Lyon, France, 23-27 April 2018.

15. Ishida, T.; Isbister, K. Digital Cities: Technologies, Experiences, and Future Perspectives; Springer: Berlin, Germany, 2002.

16. Visvizi, A.; Mazzucelli, C.; Lytras, M. Irregular migratory flows: Towards an ICT' enabled integrated framework for resilient urban systems. J. Sci. Technol. Policy Manag. 2017, 8, 227-242. [CrossRef]

17. Chui, K.T.; Alhalabi, W.; Pang, S.S.H.; Pablos, P.O.; Liu, R.W.; Zhao, M. Disease Diagnosis in Smart Healthcare: Innovation, Technologies and Applications. Sustainability 2017, 9, 2309. [CrossRef]

18. Guo, L.; Guo, D.; Wang, W.; Wang, H.; Wu, Y.J. Distance Diffusion of Home Bias for Crowdfunding Campaigns between Categories: Insights from Data Analytics. Sustainability 2018, 10, 1251. [CrossRef]

19. Wu, S.M.; Chen, T.-C.; Wu, Y.J.; Lytras, M. Smart Cities in Taiwan: A Perspective on Big Data Applications. Sustainability 2018, 10, 106. [CrossRef] 
20. Visvizi, A.; Lytras, M.D. Editorial: Policy Making for Smart Cities: Innovation and Social Inclusive Economic Growth for Sustainability. J. Sci. Technol. Policy Mak. 2018, 9, 1-10.

21. Carrasco-Sáez, J.L.; Careaga Butter, M.; Badilla-Quintana, M.G. The New Pyramid of Needs for the Digital Citizen: A Transition towards Smart Human Cities. Sustainability 2017, 9, 2258. [CrossRef]

22. Smart Cities Research: Contemporary Issues in Smart Cities Research. 2018. Available online: https:/ / docs. google.com/forms/d/e/1FAIpQLSciGvQE78AWnUcHqt4Q_MLFC6FT52UQskZSSNIZzOBJNQTdkA/ viewform (accessed on 10 June 2018).

23. Visvizi, A.; Lytras, M.D. Transitioning to Smart Cities: Mapping Political, Economic, and Social Risks and Threats; Elsevier-US: New York, NY, USA, 2019.

(C) 2018 by the authors. Licensee MDPI, Basel, Switzerland. This article is an open access article distributed under the terms and conditions of the Creative Commons Attribution (CC BY) license (http://creativecommons.org/licenses/by/4.0/). 